\title{
Intraoral self injection: II. The simulation of self-stimulation phenomena with a conventional reward '
}

\author{
JAAK PANKSEPP AND JAY A. TROWILL \\ UNIVERSITY OF MASSACHUSETTS
}

The behavior of animals self-injecting themselves with a highly appetitive solution was strikingly similar to behavior of animals responding for ESB. Fast extinction, priming, and extinction without responding were demonstrated. ESB data was best simulated by intraoral self-injection animals on an ad lib food schedule whose behavior was maintained by the incentive quality of the food reward.

Panksepp \& Trowill (1967) demonstrated that decreasing delay of reinforcement with a conventional reward did not produce the rapid extinction that is reported for free operant behavior maintained by electrical stimulation of the brain (ESB). Thus, the simple variable of delay of reinforcement is not sufficient to explain the rapid extinction found with intracranial self-stimulation.

One variable that has been largely ignored in comparisons of ESB and food based behavior is the level of deprivation under which the $\mathrm{Ss}$ are tested. Invariably, Ss trained for a food reward are at a high level of food deprivation. Though the ESB animals may be under a similar deprivation schedule, there is no guarantee that the locus of the stimulating electrode is at a site that is sensitive to levels of food deprivation. Hodos \& Valenstein (1960) noted that a relationship between drive level and self-stimulation has not been consistently found from some hypothalamic locations. Recently Deutsch \& DiCara (1967) demonstrated that rats responding for ESB at certain hypothalamic locations have greater resistance to extinction when tested at a high level of food deprivation than at a low level. Thus, a cogent comparison between ESB and conventional rewards would require that freely fed animals bar pressing for ESB be compared to animals that are allowed to self-inject themselves whlle maintained on a free feeding maintenance schedule. The initial part of this experiment was designed to compare the resistance to extinction between animals allowed to self-inject themselves with a highly appetitive solution while under a high or under a no food deprivation schedule.

The second part of the experiment was run to test whether extinction without responding could be obtained with a conventional reward. In a presentation of evidence for the drive decay hypothesis of ESB maintained behavior, Howarth \& Deutsch (1962) stated that extinction should be a simple function of time since the last electrical stimulus, and would be independent of the number of unreinforced lever presses occurring in that time. Although recent evidence (Pliskoff \& Hawkins, 1963; Stutz, Lewin, \& Rocklin, 1965) suggests that extinction without responding is not truly a time dependent process as first postulated, an adequate explanation for the effect has yet to be presented.

Method

Eight fistulated Ss that had been used in a previous experiment (Panksepp \& Trowill, 1967) were randomly divided into two groups. Four Ss were put on a $23 \mathrm{~h}$ food deprivation schedule (Group DEP), and the remainder were allowed food ad lib (Group AD LIB). The Ss were given two days of 100 acquisition trials. During these sessions each bar press activated a solenoid driven syringe which injected $.04 \mathrm{ml}$ of chocolate milk directly into the mouth of the S. On the third day, 50 reinforcements were given followed by a $15 \mathrm{~min}$ extinction session (Session 1-Table 1 ). Two days later, after a 5 min session to test for spontaneous recovery, two noncontingent priming reinforcements were given to see if the Ss would resume responding. If responding did not resume, the $S$ was reshaped. Fifty reinforced responses were then allowed and extinction responding was again recorded for $15 \mathrm{~min}$ (Session2-Table 1). During this last extinction session the DEP and $\mathrm{AD}$ LIB Ss were divided into two groups. To test for extinction without responding, one group was blocked (Group B) from responding by a hand inserted sheet of opaque plastic between the bar and the $S$ during the first 2 min of extinction, and the other group (Group NB) was not. To counterbalance for intersubject variabllity, deprivation and extinction conditions were later reversed and the Ss were retested as above. Due to equipment breakdown data was obtained for only three $\mathrm{Ss}$ in Groups $A D$ LIB-NB and $A D$ LIB-B instead of for four Ss as in Groups DEP-NB and DEP-B.

Table 1. Mean group responses during extinction and spontaneous recovery for deprived (DEP) and satiated animals (AD LIB). Letters under Session 2 designate blocked (B) and nonblocked (NB) conditions. Responses under NB-13 represent the mean responses during the last $13 \mathrm{~min}$ of extinction for NB Ss.

\begin{tabular}{lccrlll} 
Group & $\begin{array}{l}\text { Extinction } \\
\text { Responses } \\
\text { (Session 1) }\end{array}$ & $\begin{array}{c}\text { Spontaneous } \\
\text { Recovery }\end{array}$ & & \multicolumn{2}{l}{$\begin{array}{l}\text { Extinction } \\
\text { Responses } \\
\text { (Session 2) }\end{array}$} \\
\hline AD LIB & 56 & & B & NB & NB-13 \\
\cline { 3 - 6 } DEP & 149 & 16 & 35 & 57 & 22 \\
\hline
\end{tabular}




\section{Results and Discussion}

Table 1 summarizes the extinction and spontaneous recovery scores of Group DEP and Group AD LIB. The deprived group had significantly $(p<.001)$ greater resistance to extinction than the AD LIB group, and significantly $\left(p<.001\right.$ ) higher spontaneous recovery. ${ }^{2}$ This finding supports previously reported increased resistance to extinction under deprivation conditions (Heathers \& Arakelian, 1941; Saltzman \& Koch, 1948). The behavior of the AD LIB group demonstrates the ability to consistently maintain instrumental behavior in $\mathrm{Ss}$ that are on a free feeding schedule, if incentive quality of the reward is maximized. Furthermore, the range of extinction scores for Group $A D$ LIB is similar to scores obtained in our lab from Ss working for ESB in a situation where 1000 reinforcements a day are allowed for three days. Such a comparison may be more valid than a comparison with ESB groups receiving 100 rewards. Pliskoff, Wright, \& Hawkins (1965) have questioned the equality of one ESB and a normal unit of food reward. Such considerations make direct comparisons between ESB and food reward difficult. It is compelling, however, that deprivation level is crucial to measurements of resistance to extinction, and it may thus be the crucial variable that differentiates food and ESB maintained behavior.

After the spontaneous recovery session, $S$ s in Groups DEP and AD LIB were given two noncontingent reinforcements. This is analogous to priming trials that are used to elicit responding for ESB. Such priming was successful in eliciting responding from $71 \%$ and $83 \%$ of the Ss tested from Groups AD LIB and DEP, respectively. Hence a motivation inducing priming effect such as has been demonstrated with ESB can be demonstrated with a conventional reward. The low spontaneous recovery score of Group AD LIB (Table 1) suggests why priming may sometimes be necessary to induce Ss maintained at a low drive level to respond for $\mathrm{ESB}$.

Table 1 also presents evidence that extinction without responding can be induced in an animal at a low level of food deprivation whose responding has been maintained by the incentive properties of the reward. Group DEP-B Ss had significantly $(p<.057)$ more responses during extinction than DEP-NB Ss during the corresponding $13 \mathrm{~min}$ of extinction. There was, however, no significant difference $(p>.20)$ between the extinction responding of AD LIB-B Ss and the last 13 min of $A D$ LIB-NB Ss. These data suggest that a process similar to the one demonstrated in ESB animals who are initially not allowed to respond during extinction is also working in nondeprived Ss working for an intraorally administered high incentive food reward.
Incidental observations during the experiment revealed striking similarities between rats rewarded by direct oral injections of the highly palatable solution and rats rewarded by ESB to certain brain areas, particularly the lateral hypothalamus and medial forebrain bundle. The Ss displayed pronounced agitation as reflected by bar biting and rapid changes in position. These effects increased as the quantity of the injected solution decreased, but decreased across sessions.

We feel that by manipulation of drive level and qualitative and quantitative incentive variables, most of the behavior elicited from animals rewarded with ESB can be simulated with the intraoral self-injection preparation and conventional rewards. The behavioral similarities that have been demonstrated here are rapid acquisition, rapid extinction, agitation and excitement accompanying responding, priming effects, and extinction without responding. Since the rapid extinction and extinction without responding were only demonstrated in Ss maintained at a low level of food deprivation, we feel that under satiation conditions animals whose behavior is maintained by the immediacy and palatability of the reward are most similar to animals whose behavior is maintained by ESB. This suggests that a strong incentive or expectancy component ellcited in the two preparations is the crucial similarity between them.

\section{References}

DEUTSCH, J. A., \& DiCARA, L. Hunger and extinction in intracranial self-stimulation. J. comp. physiol Psychol, 1967, 63, 344347. HEATHERS, G. L., \& ARAKELIAN, P. The relationship between strength of drive and rate of extinction of a bar-pressing reaction in the rat. J. gen. Psychol, 1941, 24, 243-258.

HODOS, W., \& VALENSTEIN, E. S. Motivational variables affecting the rate of behavior maintained by intracranial stimulation. J. comp. physiol Psychol, 1960, 53, 502-508.

HOWARTH, C. I., \& DEUTSCH, J. A. Drive Decay: The cause of fast "extinction" of habits learned for brain stimulation. Science, 1962, 137, 35-36.

PANKSEPP, J., \& TROWILL, J. A. Intraoral self injection: I. Effects of delay of reinforcement on resistance to extinction and implications for self-stimulation. Psychon. Sci., 9, 405-406.

PLISKOFF, S. S., WRIGHT, J. E., \& HAWKINS, D. T. Brain stimulation as a reinforcer: intermittent schedules. J. exp. Anal Behav. 1965, $8,75-88$.

SALTZMAN, I., \& KOCH, S. The effect of low intensities of hunger on the behavior mediated by a habit of maximum strength. J. exp. Psychol, 1948, 38, 347-370.

STUTZ, R. M., LEWIN, I., \& ROCKLIN, K. W. Generality of "drive-

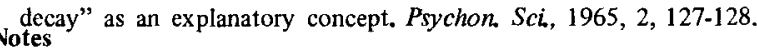

1. This research was supported by USPHS Grant No. MH 13155-01 awarded to the second author.

2. All statistical tests were done with the Mann-Whitney $U$ test. 